OPEN ACCESS

Edited by:

Elizabeth Mendenhall, The University of Rhode Island, United States

Reviewed by:

Timo M. Koivurova,

University of Lapland, Finland Miriam C. Balgos,

Global Ocean Forum, United States Linda Kay Silka,

University of Maine, United States

*Correspondence:

Tymon Zielinsk

tymon@iopan.pl

Patrycja Mrowiec

p.mrowiec@storware.eu

Specialty section:

This article was submitted to Marine Affairs and Policy,

a section of the journal

Frontiers in Marine Science

Received: 20 October 2020 Accepted: 13 January 2021

Published: 22 February 2021

Citation:

Zielinski T, Bolzacchini E, Evans K Ferrero L, Gregorczyk K, Kijewski T,

Kotynska-Zielinska I, Mrowiec P,

Oleszczuk B, Pakszys $P$,

Piechowska E, Piwowarczyk J, Sobieszczanski J and Wichorowski M (2021) Abundance of Environmental

Data vs. Low Public Interest in Climate and Ocean Issues. Where Is the Missing Link?

Front. Mar. Sci. 8:619638. doi: 10.3389/fmars.2021.619638

\section{Abundance of Environmental Data vs. Low Public Interest in Climate and Ocean Issues. Where Is the Missing Link?}

\author{
Tymon Zielinski ${ }^{*}$, Ezio Bolzacchini ${ }^{2}$, Karen Evans ${ }^{3}$, Luca Ferrero ${ }^{2}$, Klaudia Gregorczyk ${ }^{1}$, \\ Tomasz Kijewski ${ }^{1}$, Izabela Kotynska-Zielinska ${ }^{4}$, Patrycja Mrowiec ${ }^{5 *}$, Barbara Oleszczuk ${ }^{1}$, \\ Paulina Pakszys ${ }^{1}$, Ewa Piechowska ${ }^{1}$, Joanna Piwowarczyk ${ }^{1}$, Jan Sobieszczanski ${ }^{5}$ and \\ Marcin Wichorowski ${ }^{1}$

\begin{abstract}
${ }^{1}$ Institute of Oceanology, Polish Academy of Sciences, Sopot, Poland, ${ }^{2}$ GEMMA and POLARIS Research Centre, Department of Earth and Environmental Sciences, University of Milano-Bicocca, Milan, Italy, ${ }^{3}$ Commonwealth Scientific and Industrial Research Organisation (CSIRO), Canberra, NSW, Australia, ${ }^{4}$ Today We Have, Sopot, Poland, ${ }^{5}$ Storware, Warsaw, Poland
\end{abstract}

Climate change and associated modification of the ocean is a fact, however, it seems to be the most undervalued and little understood "pandemic" challenge of this century. We live in a world where environmental data is increasingly being amassed and models are generating finer scale and increasingly dense numbers of outputs, resulting in the production of high level scientific information on climate and ocean. However, the knowledge generated is often inaccessible, incomprehensible and misunderstood by society. Given that society has access to many levels of information through various forms of media, how do we better share this knowledge, and improve understanding of how society is impacting their immediate and remote surroundings and what behavioral changes are needed for reducing those impacts? In this paper, we assess the level of environmental and ocean awareness among young learners. We argue that, despite the wide range of environmental data available and a common use of a broad range of media, this group is not aware of or interested in climate related issues. This paper highlights the challenges in bringing researchers, data managers and educators together to provide consistent, up-to-date messages that can appeal to and can be understood by modern societies. It also highlights insufficiencies in environmental school education, including those concerning the "uncertainty" concept, which is a fundamental part of any scientific process. In identifying these challenges, we propose a pathway for improving societal knowledge on climate and ocean changes that takes advantage of the technological abilities for environmental data collection, storage and processing, global and regional research, as well as good practices in ocean literacy and climate and ocean education.

Keywords: climate and ocean change, climate adaptation and mitigation, environmental data and observations, integrated knowledge sharing, climate and ocean literacy 


\section{INTRODUCTION}

The Sustainable Development Goals (SDGs) represent an agreed international vision for the future and provide a framework for actions to make the Earth a better place for all ${ }^{1}$. This vision is focused on creating strategies that: "build economic growth and address a range of social needs including education, health, social protection, and job opportunities, while tackling climate change and environmental protection" (see text footnote 1). In order to succeed, these strategies must be supported by scientific information and must be effectively communicated to all stakeholders, so that science-based and well informed decisions can be facilitated (Holliman and Jensen, 2009; Ferrero et al., 2013, 2015; Patterson et al., 2017; UNEP, 2019; Jensen and Gerber, 2020; Kotynska-Zielinska et al., 2020; Terorotua et al., 2020; Wisz et al., 2020).

Thus, the importance of the role of science in achieving the SDGs has been highlighted in Chapter 35 of Agenda $21^{2}$ of the United Nations Conference on Environment \& Development, held in Rio de Janeiro in 1992. This included:

1. Strengthening the scientific basis for sustainable management,

2. Enhancing scientific understanding,

3. Improving long-term scientific assessment and,

4. Building up scientific capacity and capability.

During the UN World Summit on Sustainable Development, held in 2002, a Plan of Implementation of SDGs was accepted (A/CONF.199/L.7). It highlighted the crucial role of sciencebased decision-making, through: “integrating scientists' advice into decision-making bodies; partnerships between scientific, public and private institutions; improved collaboration between natural and social scientists, and establishing regular channels for requesting and receiving advice between scientists and policy makers; making greater use of integrated scientific assessments, risk assessments and interdisciplinary and intersectoral approaches; increasing the beneficial use of local and indigenous knowledge" (Report of the World Summit on Sustainable Development, 2002a). The document defined tools for actions to strengthen science-based decision-making and communication of knowledge. Those included: appropriate information and communication technologies, creation of national statistical services for provision of quality data, data assessment models, accurate databases and integrated information systems (Report of the World Summit on Sustainable Development, 2002b).

During the United Nations Conference on Sustainable Development, in 2012, the final adopted document, The Future We Want, which called for global sustainable development contained an agreement to support actions to bring together all information and existing assessments, to strengthen the sciencepolicy interface (Paragraph 85.k), information that had been previously greatly dispersed.

In 2014, the United Nations Secretary-General set the priority for the Division for Sustainable Development of the

\footnotetext{
${ }^{1}$ https://www.un.org/sustainabledevelopment/

${ }^{2}$ https://sustainabledevelopment.un.org/outcomedocuments/agenda2 1
}

Department of Economic and Social Affairs to analyze and evaluate the scientific potential for the implementation of sustainable development. A report was launched to facilitate dialogue between scientists and decision-makers, which then led to the development of the goals in 2015 (The Millennium Development Goals Report, 2014).

Recognizing that a transformation in science was needed to secure a sustainable ocean future, through the 2017 Resolution A/RES/72/73, the UN General Assembly proclaimed the UN Decade of Ocean Science for Sustainable Development (20212030) (the Decade) and mandated the Intergovernmental Oceanographic Commission to prepare an Implementation Plan in consultation with Member States, UN partners and other relevant stakeholders (IOC/EC-LI/2 Annex 3, 2018).

With just over 10 years to achieve the 2030 Agenda the UN Secretary-General in 2019 appealed to world communities to mobilize a decade of action to achieve the SDGs. The call for actions has been made at three levels, with the third level calling on the media, academia and many other stakeholders, to secure the process of necessary transformations for achieving the SDGs ${ }^{3}$.

The Decade of Action to achieve the SDGs, through the Agenda 2030, is tasked with facilitating global communication and mutual learning across research and stakeholder communities. The outputs are aimed at meeting the needs of scientists, policy makers, industry, civil society and the wider public. In doing so, it calls for the development of new, collaborative partnerships that can deliver more effective science-based management of the oceans and its resources (Pendleton et al., 2020). It promotes a more targeted and effective information flow as well as innovative ways of conducting and using ocean science ${ }^{4}$.

All of these declarations and agreements clearly state the importance of science-based decision-making. However, effective instruments and services are needed to be able to effectively communicate science-based knowledge to all stakeholders.

In order to address the changes already occurring in the Earth's climate and ocean and those still to come, humans must identify adaption pathways that involve transforming their lifestyles. This will require science-based knowledge to build their capacity to realize effective adaptation (Jensen and Gerber, 2020; Pendleton et al., 2020).

Unfortunately, there are still plentiful and easily available fake and/or pseudo-scientific ideas, which promote a wrong picture of the environmental changes and the human role in them. Therefore, achieving actions that facilitate mitigation, adaptation and transformation will require that citizens have access to science-based knowledge to build their capacity (Koutsopoulos et al., 2019). Although, knowledge and awareness are important preconditions for behavioral change, they are often not sufficient. Various models suggest various additional factors (Kollmuss and Agyeman, 2010; Stoll-Kleemann, 2019) that need to be included in shaping pro-environmental or pro-marine behavioral change. Creating personal relation or personal responsibility for

\footnotetext{
${ }^{3}$ https://www.un.org/sustainabledevelopment/development-agenda/

${ }^{4}$ https://en.unesco.org/ocean-decade
} 
the ocean is among one of the most commonly mentioned (McKinley and Fletcher, 2012).

Here, we describe the climate/ocean related programs and their elements that are generating knowledge, which we have divided into three levels: global, regional and local. The choice of the systems described reflects the authors involvement in various science organizations/programs. We also discuss the results of educational initiatives in which authors have been involved with in understanding the level of awareness of ocean and climate issues among young learners and the results they have so far provided. Using this information we then discuss the extent of outreach associated with each program.

Through this process we provide the context relating to the level of the available climate and ocean knowledge. We also discuss and provide conclusions on the reasons for certain types of attitudes, respondents revealed in the studies and argue for necessary future actions in order to increase the general knowledge and thus awareness of climate and ocean issues. In doing so, we provide examples of best practices in climate and ocean approaches to share properly tailored knowledge.

\section{THE NEED FOR KNOWLEDGE GENERATION}

According to the IPCC, climate change adaptation involves: "the process of adjustment to actual or expected climate and its effects," while the climate change mitigation, involves: "human intervention to reduce the sources or enhance the sinks of greenhouse gases" (IPCC, 2014). Climate change actions may be a single, independent process or a part of a complex plan ${ }^{5,6}$.

Properly designed, climate change action plans must ensure:

1. An assessment of impacts, vulnerability and risks.

2. Proper planning for actions.

3. Implementation of action measures.

4. Monitoring and evaluating of action steps.

The United Nations and their various bodies (e.g., Global Adaptation Network and Global Centre of Excellence on Climate Adaptation, World Adaption Science Programme, National Adaptation Programs) have developed a number of approaches and hence initiatives to address climate change adaptation and mitigation. These initiatives are aimed at promoting science for climate change adaptation policy and actions through provision of research data and knowledge on climate and ocean changes and their impacts and enabling science-based knowledge transfer and sharing (see text footnote 6). In order to achieve their aims, these, climate and ocean change related initiatives need to be well designed,should incorporate the best available sciencebased knowledge, supported by adequate resources and tools and identify solutions for future actions.

In order to secure effective science-based decision making, one of the important roles of researchers and educators is to enhance

\footnotetext{
${ }^{5} \mathrm{https} / /$ www.unenvironment.org/explore-topics/climate-change/what-we-do/ mitigation

${ }^{6} \mathrm{https} / /$ /www.unenvironment.org/explore-topics/climate-change/what-we-do/ climate-adaptation
}

understanding of the importance of science and its relevance to the lives of citizens (Kopke et al., 2019; Jensen and Gerber, 2020). There is also a need to develop well-functioning and, effective mechanism for transferring science-based knowledge to citizens across the world (Rubio-Iglesias et al., 2020). Knowledge sharing in the twenty-first century is largely delivered through the development of internet-based and media-related resources (Kahila et al., 2020; Peters, 2020). However, in the case of delivery of knowledge into schools, in many cases, schools do not follow this development and still teach irrespective of learners' own experience and skills. Further application of gained knowledge is rarely presented (Fauville et al., 2018; Fischer et al., 2019; Kotynska-Zielinska et al., 2020). This lack of utilization of effective knowledge sharing tools has the potential to result in a decreasing understanding of science and common abandoning of critical thinking. This endangers the process of decision making itself, particularly at a time when societies are striving to involve an increased number of citizens in climate and ocean related decision making and development of solutions (Zins, 2007; Jensen and Gerber, 2020; Terorotua et al., 2020).

In a simplified approach, the process of creating knowledge involves collection of data, then preparation of information and finally, creation of knowledge (Serban and Luan, 2002; Zins, 2007). However, there are various types of data and knowledge, as shown in Table 1 (modified from: Cambridge International Examinations 2015, 2017). "The first Global Integrated Marine Assessment was published in 2017 (UN, 2017a)".

More than 2400 years ago, Plato in his dialogues, pointed out that raw data provide no information, however, without good quality data it is impossible to build knowledge. In order to transform data into meaningful information, the data needs to be analyzed and interpreted (Serban and Luan, 2002; Zins, 2007). Data collected as part of a well-designed study once properly analyzed and hence processed with appropriate context should become a foundation of information (Hedlund, 1994).

Knowledge can be regarded as the result of understanding information, and as such it can be attributed to Cambridge International Examinations 2015 (2017):

1. Acquiring and remembering a set of facts, i.e., explicit knowledge.

TABLE 1 | Definitions of data, information and knowledge.

\begin{tabular}{ll}
\hline Term & Description \\
\hline Raw data/data & $\begin{array}{l}\text { The raw input of text, numbers and symbols in raw or } \\
\text { unorganized form that needs to be processed to give it } \\
\text { meaning. }\end{array}$ \\
Information & $\begin{array}{l}\text { Data that has been processed, e.g., grouped, normally by a } \\
\text { computer, to give it meaning and make it interpretable. }\end{array}$ \\
Explicit knowledge & $\begin{array}{l}\text { Knowledge, such as facts, that can be easily passed on to } \\
\text { others. }\end{array}$ \\
Knowledge & $\begin{array}{l}\text { The acquisition by a person of information such as facts, or } \\
\text { the understanding of information such as how to solve } \\
\text { problems. } \\
\text { Tacit knowledge }\end{array}$ \\
& $\begin{array}{l}\text { Knowledge that is difficult to pass on to someone else, } \\
\text { such as knowing how to do something. }\end{array}$
\end{tabular}


2. The use of information to solve problems, i.e., tacit or implicit knowledge.

Explicit knowledge is rather easy to document and share and involves, e.g., codified information given in instructions, dictionaries or course books (Hedlund, 1994).

Tacit knowledge is subjective, and therefore can be difficult to capture and difficult to pass on to others. It often includes knowledge on how to do something and can involve experimental elements of knowledge (e.g., that associated to personal experience or even intuition). Its transfer requires personal contact or other forms of social interactions (networking). Based on these varying terms, we define knowledge as a function of the following elements:

Knowledge $\sim<$ data; information; experience; context; application >

At the beginning of the process of creation of knowledge, appropriate design and then accurate collection of any type of data (e.g., environmental data) is key. Well-designed knowledge creation facilitates expanded sharing of research outputs, which may lead to:

1. Increased digital availability and usability of information.

2. Increased scope of digitally available sciencederived resources.

3. Increased quality of digitally shared data.

4. Facilitation of data use in many ways including reuse.

5. Enhanced interoperability and open access to digitally shared research data.

6. Improved competences of people involved in digital sharing and re-use of science resources.

However, instead of maximizing the use of data, hence information, a multitude of data is often stored "in drawers," and thus much information that can be useful for reproducing small and large environments, species, or the climate becomes unavailable. However, such data once damaged or lost can't be reproduced. Backup processes, and the archiving original data are essential components of data management, and thus protecting the potential for creating/increasing knowledge.

A typical problem in communicating science-based information to the general public relates to the fact that formal education is usually slow to innovative approaches and change and teachers still rarely reach to direct sources/researchers, instead relying on simply passing information provided in text books (explicit knowledge) to their classrooms (Donert, 2018; Kopke et al., 2019; Kotynska-Zielinska et al., 2020). In doing so, many school students therefore do not have the chance to learn about the process of knowledge generation, including data collection, and the process involved in conversion of data into information. Students, instead, simply learn information to repeat (i.e., rote learning), which is deprived of the other knowledge elements, i.e., context, experience and application (Donert, 2018; Fauville et al., 2018; Fischer et al., 2019).

Knowledge, when provided in such manner, is often incomprehensible and misunderstood. This is particularly the case for data on the state of the world, including issues related to global change, the environment and the ocean (Sundblad et al., 2009). There is also a problem of cognitive capacities, i.e., the overload of the available information that makes it difficult to reflect on the issues and gain a deeper knowledge on various issues (Sibbel, 2009; Donert, 2018). Another problem as described by McCauley et al. (2019), is that, "there is a lack of understanding of the importance of the ocean in our cultural, social, and environmental heritage, which makes it more difficult to deal with the issue at hand." These challenges are further exacerbated by regional and socioeconomic inequalities which can influence the resources available to teachers and students.

In addition, there is a need to have tools or known mechanisms to distinguish between "knowledge" and "propaganda" (Bawden and Robinson, 2008; Kopke et al., 2019; Terorotua et al., 2020), and this is missing in typical education. These are important elements in the climate change debate. Without access to and an understanding of science-based knowledge people reach for easy solutions, often that do not require critical thinking leading to the creation of inaccurate or inappropriate knowledge (Williamson, 2016; Donert, 2018).

\section{Climate and Ocean Programs and Their Outreach}

For the purpose of this paper, we identified three groups of climate and ocean programs, with regard to their focus and extent of outreach, and utilized the authors involvement in a range of science-based and information brokering programs to provide relevant case studies.

\section{Global Programs}

Reports produced by the Intergovernmental Panel on Climate Change (IPCC) and the World Ocean Assessments produced as part of the UN Regular Process are the most recognized global environmental knowledge collection. The scope of the reports produced by the IPCC has expanded since its inception in 1988. Not only they focus on the hard science results concerning climate, but also explore the implications of a changing environment through a scenario driven impact assessment approach. They also identify adaptation and mitigation actions that are needed to address those impacts. The reports have assisted in consolidating agreement throughout the scientific community (on climate change issues) and have helped guide priorities for interdisciplinary research (Hulme and Mahony, 2010).

Report preparation involves several independent review steps, providing objectivity and transparency to the process. These reviews involve the engagement of hundreds of experts from a range of scientific, technical and socio-economic fields, who evaluate the content of the reports. The Assessment Reports are the flagship outcome of the IPCC, with the first Assessment Report (AR1) catalyzing political negotiations on climate change and the development of the Framework Convention on Climate Change (Beck, 2011). The most recent fifth Assessment Report (AR5) was published in 2014, and provided: "an overview of the state of knowledge concerning the science of climate change, 
emphasizing new results since the publication of the IPCC Fourth Assessment Report (AR4) in 2007." "7 The main messages provided by the AR5 are included in the four Headline Statements (IPCC, 2014):

1. "Human influence on the climate system is clear, and recent anthropogenic emissions of green-house gases are the highest in history. Recent climate changes have had widespread impacts on human and natural systems."

2. "Continued emission of greenhouse gases will cause further warming and long-lasting changes in all components of the climate system, increasing the likelihood of severe, pervasive and irreversible impacts for people and ecosystems. Limiting climate change would require substantial and sustained reductions in greenhouse gas emissions which, together with adaptation, can limit climate change risks."

3. "Adaptation and mitigation are complementary strategies for reducing and managing the risks of climate change. Substantial emissions reductions over the next few decades can reduce climate risks in the 21st century and beyond, increase prospects for effective adaptation, reduce the costs and challenges of mitigation in the longer term and contribute to climate-resilient pathways for sustainable development."

4. "Many adaptation and mitigation options can help address climate change, but no single option is sufficient by itself. Effective implementation depends on policies and cooperation at all scales and can be enhanced through integrated responses that link adaptation and mitigation with other societal objectives."

Importantly, each report is fully accessible to anyone via the IPCC's website, with summaries that distill reports into key messages at different levels of scientific competence. The IPCC also actively engages in the distribution of information on its reports, through its presence on all major social media platforms, including: Facebook, Twitter, Youtube, Instagram, Linkedln, Vimeo, and Slideshare. Key messages are further distilled through these platforms with links to primary reports.

In a similar way, the Global Integrated Marine Assessments (also known as the World Ocean Assessments) are outputs of the first and second cycle of the Regular Process for Global Reporting and Assessment of the State of the Marine Environment (including Socioeconomic Aspects) $)^{8}$. The Regular Process was established by the United Nations General Assembly, to address a number of needs including improving scientific assessment of the marine environment in order to strengthen the science basis for policy making.

The purpose of the assessment is to facilitate the following objectives (Evans et al., 2019):

1. Integration of ocean observations/services.

2. Improving ocean literacy and societal connections to the ocean.

${ }^{7}$ https://www.ipcc.ch/

${ }^{8}$ https://www.un.org/regularprocess/
3. Finding information delivery pathways to key stakeholders.

4. Improvements in the science-policy interface.

Hundreds of scientists from various disciplines and geographic regions, are led by a Group of Experts, in conducting assessments on the state of marine biodiversity and habitats, marine industries, human use of the ocean and associated planning and management approaches to that use. The first Global Integrated Marine Assessment was published in 2017 (UN, 2017b) with the Second Assessment due in early 20219. Both of the assessments provide scientific basis for the consideration of ocean issues by decision makers as well as other bodies, involved in ocean affairs.

The Assessments reflect the scale and complexity of ocean processes. They identify the main knowledge and capacity gaps providing a guidance on where efforts should be placed in a better understanding, conserving and maintaining the ocean. Both Assessments provide relevant information to the achievement of the UN 2030 Agenda for Sustainable Development; a targeted technical abstract summarizing these information produced, as part of the First Regular Process (UN, 2017b).

A key element of the Regular Process is outreach and awareness-raising, realized through the establishment of partnerships with relevant stakeholders, organization of briefings and side events at relevant fora, including global meetings, distribution of information material across organizations, throughout the scientific community and the public (see text footnote 8). Through the UN, the Regular Process is linked to all major social media platforms, including: Facebook, Twitter, Youtube, Instagram, Pinterest, and Flickr.

Average outreach and visibility of an individual scientist, independent of the discipline, counted as a number of citations, rarely exceeds 1,000 citations over a course of the entire research career (an author's own rough estimate based on the analyses of over 100 climate related researcher's citation reports in the Web of Knowledge). These citations are related to works of colleagues from the very discipline and are made in very specialized journals. Therefore, knowledge created by researchers during their research life, despite being often fundamental for the development of the global societies, is actually very limited in direct outreach to a narrow group of experts in the field. This is one of the most important gaps in the transfer of science-based knowledge to global society.

\section{Regional/Local Programs}

The Svalbard Arctic Earth Observing System (SIOS) is a regional observing system, currently contributed by 24 member institutions from nine countries ${ }^{10}$. The aim of SIOS is to integrate existing observational infrastructure to facilitate environmental studies in the region of Svalbard; in doing so SIOS provides research facilities and services that add value and facilitate collaborations between partners. Such integrated system allows for comprehensive approach to address questions, mostly related to climate change. This way, SIOS provides opportunities to

\footnotetext{
${ }^{9}$ www.un.org/Depts/los/woa

${ }^{10}$ https://sios-svalbard.org/
} 
conduct research and, hence facilitates acquisition of wide range of environmental data and creation of fundamental knowledge regarding environmental change, of global relevance (see text footnote 10).

The SIOS focuses on interactions of processes across five climate related areas: the biosphere, geosphere, atmosphere, cryosphere and hydrosphere. The core of the SIOS consists of a Science Optimization Service: a platform for interdisciplinary communication and collaboration (see text footnote 10) that also guides the scientific priorities of SIOS, including data collected by the system. Key outputs produced by the system are the "State of Environmental Science in Svalbard" (SESS) reports (Orr et al., 2019; Van den Heuvel et al., 2020), that annually summarize the state of Earth System Science conducted by the partners, highlight research needs and recommend future priorities for the observing system (Orr et al., 2019; Van den Heuvel et al., 2020). The SESS report is instrumental to exploring, developing and defining the next generation of core data and thus guides research across the Svalbard region. It is focused on describing the state of the monitoring activities and the benefits of the use of the SIOS services.

The SIOS Knowledge Centre coordinates the system with the support of a number of working groups, ensuring the sustainability and maintenance of the system, while the Communication Service provides information about the System activities, developments, and System related activities within the member institutions (see text footnote 10). The Communication Service, through the SIOS website and a regular newsletter, provides information and outreach material for conferences, facilitates networking and provides details of relevant training and collaboration opportunities ${ }^{11}$.

In terms of the visibility of each of the described programs and actions, including social media, the following table compares the IPCC, Regular Process, SIOS with respect to the four major social media platforms, i.e., FB, Twitter, Instagram, and the Youtube. Table 2 below presents numbers or estimated numbers of viewers or observers (social media) as of 5 August 2020.

It is clear that the IPCC has the most developed social media-based outreach and communication system, with the greatest number of followers/subscribers. Astonishingly, despite having the UN actively engaging in social media, the Regular

${ }^{11}$ https://sios-svalbard.org/Newsletter

TABLE 2 | Outreach and communication impact of IPCC, Regular Process, and SIOS (number of followers/subscribers).

\begin{tabular}{|c|c|c|c|c|}
\hline Program & Facebook & Instagram & Twitter & Youtube \\
\hline IPCC & 81,860 & 41,400 & 213,700 & 13,500 subscribers \\
\hline Regular & No individual & No individual & No individual & No individual \\
\hline Process & $\begin{array}{l}\text { account, } \\
\text { information } \\
\text { provided } \\
\text { through the } \\
\text { UN. }\end{array}$ & $\begin{array}{l}\text { account, } \\
\text { information } \\
\text { provided } \\
\text { through the } \\
\text { UN. }\end{array}$ & $\begin{array}{l}\text { account, } \\
\text { information } \\
\text { provided } \\
\text { through the } \\
\text { UN. }\end{array}$ & $\begin{array}{l}\text { account, } \\
\text { information } \\
\text { provided through } \\
\text { the UN. }\end{array}$ \\
\hline SIOS & 252 & Non-existent & 275 & Non-existent \\
\hline
\end{tabular}

All numbers acquired on 5 August 2020.
Process, nor the Division for Ocean Affairs and the Law of the Sea (DOALOS, the Secretariat for the Regular Process), nor the Office of Legal Affairs (under which DOALOS sits) have social media accounts (unlike other parts of the UN system such as UNESCO, UNEP, UNHCR, etc.), and all press releases, rather than sitting on the website for the Regular Process or on the DOALOS website can only be found on the United Nations website (only one press release is available on the Regular Process website dating back to January 2016). Although SIOS, has a developed communication system and pre-described communication activities, its social media outreach is limited to two platforms, with just over 500 followers.

\section{Youth Awareness of Climate and Ocean Issues}

Here we explore current youth awareness of climate and ocean issues using the "Ocean of Changes program of interdisciplinary workshops"12 and the "I Live by the Sea summer School"13 as case studies.

The "Ocean of Changes workshops" are dedicated to school students of ages $8-18$ with the aim of mutually sharing knowledge on marine environments and marine protection issues (knowledge as defined in formula 1 is the core of this idea, with tacit knowledge of key importance). Groups of participants are tasked with generating topics to increase the general awareness of good practices in climate and ocean mitigation and adaptation actions (including the Sustainable Development Goals). The expectation is that the groups then develop ideas for promoting actions, sharing good practice methods, etc.

Through questionnaires conducted at the initial and final stages of the workshops and the projects created by the young learners, the role of young people in supporting community led actions on marine sustainability, marine pollution, climate action, and community resilience (through engagement and outreach) can be assessed. During the workshops, the groups of participants were posed with the following questions:

1. Which engagement activity/methodology is most useful for community groups?

2. What resources can scientific organizations provide to support community action?

3. What format of communication and engagement (infographic, brief, video, presentation, etc.) is most effective?

As part of the activities of the program students generate:

1. Ready actions for the promotion of ocean related issues with solutions proposed.

2. Tips on accelerating community led action on sustainability.

3. Community networks, with a particular focus on young learners.

During the boreal fall/winter 2019/2020 workshops, involving 296 young Polish learners, were divided into three age groups

\footnotetext{
${ }^{12} \mathrm{http}: / /$ www.iopan.gda.pl/odn2019/sdn/index-eng.html

${ }^{13} \mathrm{http}: / /$ www.todaywehave.com/I_live_by_the_Sea_Summer_School.html
} 
of comparable size. When posed with the question "Do you have an impact on the ocean?" responses of "I don't know" progressively decreased with age while "Yes" responses increased with age (Figure 1).

Differences in "Yes" answers between age groups were found to be significantly different using a chi-squared test $(p<0.01)$. Responses of "No" were relatively consistent across age groups ranging $11 \%$ in the $8-11$ year group to $15 \%$ in the other two age groups (Figure 1).

When posed with the question "Where do you gain knowledge about the ocean from?" media-based sources dominated across all age groups (Figure 2).

All age groups identified nature films (i.e., documentaries on animals plants or other non-human living creatures that could be focused on natural habitats but also included footage of captive or trained animals) followed by documentary films (i.e., documentation of reality primarily for the purposes of instruction or education) as important, with educational workshops increasing in importance with age. Answers in the three age groups were not significantly different. Interestingly, the importance of books, including textbooks declined with age. This suggests that students seek tacit knowledge rather than explicit knowledge provided through textbooks, which suggests the shift of their focus from hard copy sources of information to digital sources. The role of workshops in knowledge transfer was also significant for learners.

The responses of learners who attended workshops in 2019/20 were similar to those provided by Polish $(n=274)$ and Lithuanian ( $n=80$ ) young learners involved in workshops with a focus on Arctic issues held in 2018. Workshops held in 2018 suggested that the majority of Polish students were not particularly interested in information/knowledge on the Arctic region with participants identifying that they were more interested in jungle environments, hot deserts and oceanic islands.

When posed with the question "Where do you gain your knowledge about the Arctic from?" students across all age groups in the 2018 workshops, similarly to those in $2019 / 20$ identified that their main sources of information included documentaries and nature films (Kotynska-Zielinska et al., 2020). When broken down into types of school systems (public vs semiprivate/autonomous), both types of schools identified that nature films and documentaries are important sources of information regardless of the age group (Figure 3).

Workshops also identified that, school lessons are an important source of information for students, while educational workshops were mostly important to younger students. Comparisons between the age groups using chi-squared tests were not significantly different. Relatively low interest in environmental issues among young learners is not surprising, and has been described by many researchers (Zusho et al., 2003; Vedder-Weiss and Fortus, 2011; Gordon Foundation, 2015; Heddy and Sinatra, 2017; Fauville et al., 2018).

The "I Live by the Sea Summer School" 2020, consisted of six webinars, run in July and August. The goal of this program was to facilitate an interdisciplinary platform for discussions on climate and ocean related issues and enable the exchange of information between participants from different parts of the world, who care about the state of the natural environment. Transferring tacit knowledge, was central to this effort. Webinars were open to the public, and all meetings were recorded. As of October 2020,

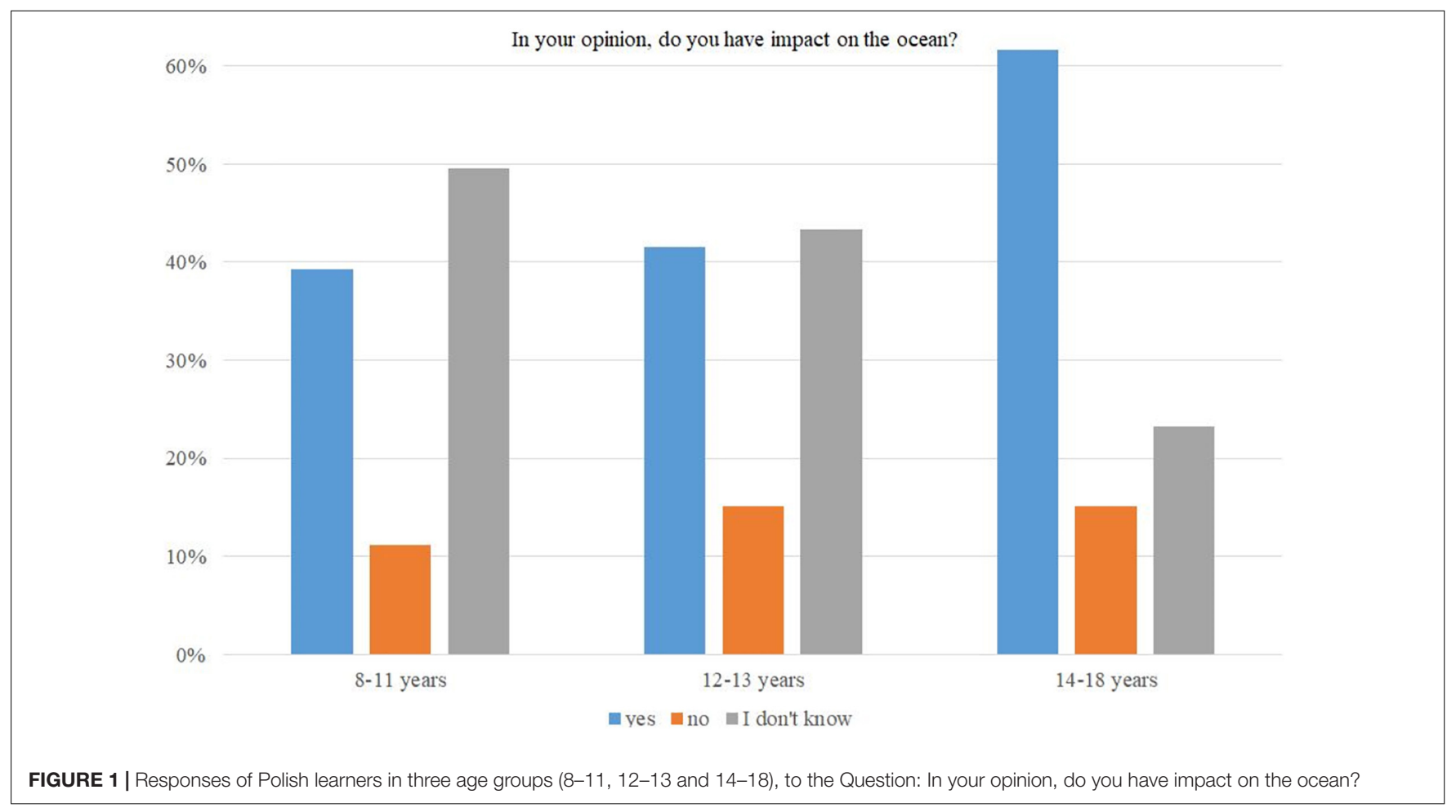




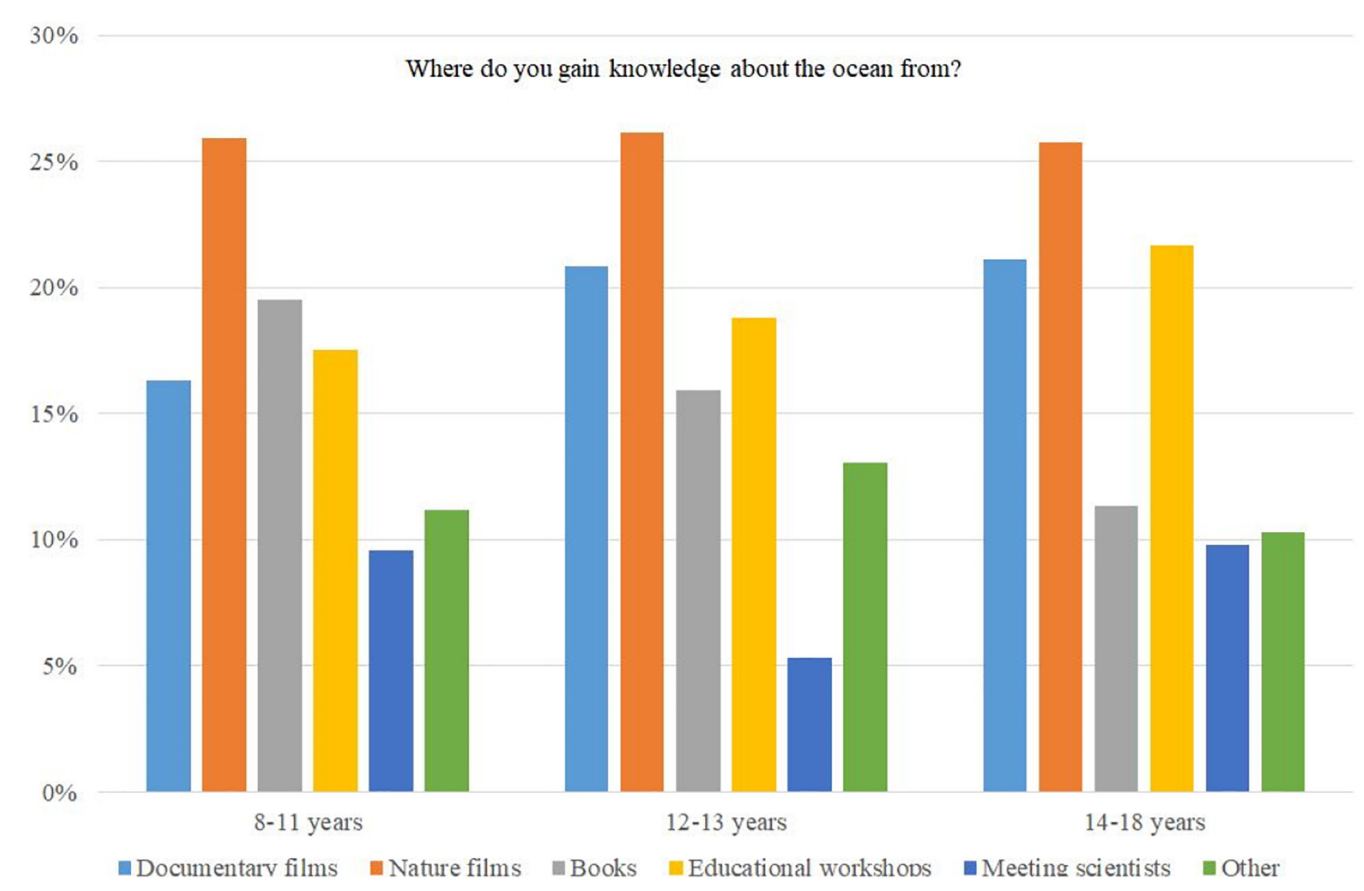

FIGURE 2 | Results associated with the question: "Where do you gain knowledge about the ocean from?" posed to age groups during workshops conducted in $2019 / 2020$.
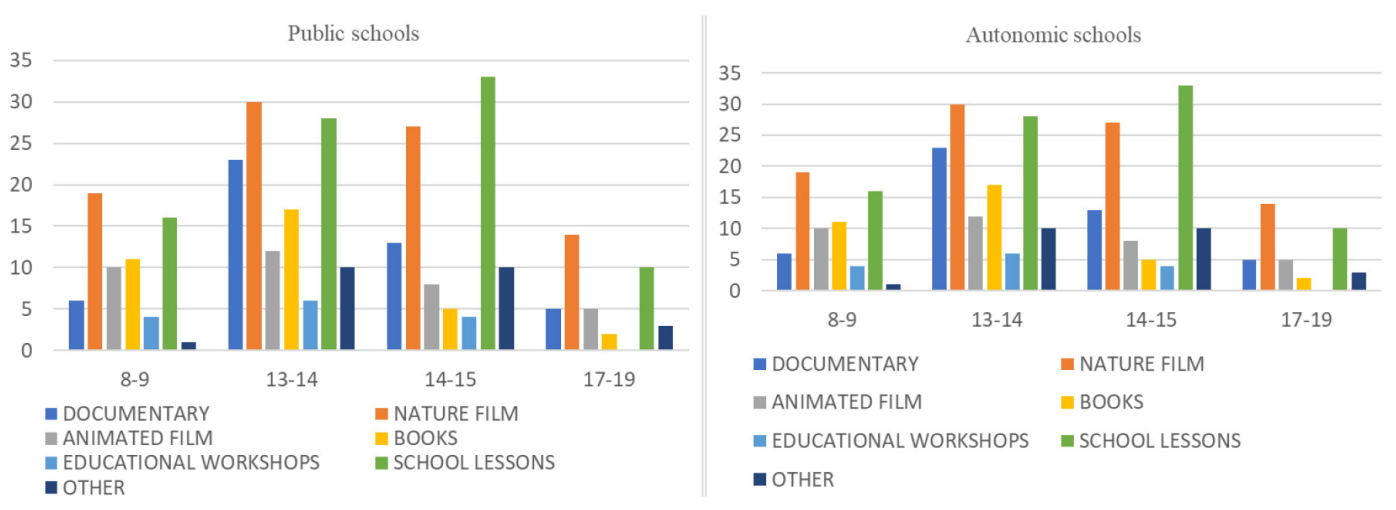

FIGURE 3 | Results associated with the question "Where do you gain your knowledge about the Arctic from?"

the recordings were viewed by over 13,000 people, of whom approximately $86 \%$ watched the entire seminars (Table 3 ).

\section{Improving Delivery of Climate and Ocean Information to the Public}

It is clear that if youth awareness of climate and ocean issues is to be improved, novel pathways are needed for delivery of information. We believe that scientists/research institutions could/should create "information hubs" on a local, regional, and/or global scale. These hubs may provide a broader perspective-a knowledge base that brings together processed data, and present it in a legible form allowing for the creation of useable information. To create such a "hub," science needs to use modern marketing tools that will allow it to communicate effectively with potential users. The focus of such hubs must center around involving the community in activities mitigating and adapting to climate and ocean changes.

Powerful information (in its message and impact) must be appropriately prepared, developed, and dispersed. Although the etymology of the word "university" is in the Latin word "Universitas," meaning universe and universality, scientific knowledge produced by universities is still in many cases unavailable to the public. Scientific institutions, that hold relevant data on climate change, predominantly focus their communications to the science community (stressed by national mechanisms of quality evaluations) and often fail to communicate effectively with the broader community. 
TABLE 3 | The extent of outreach of the "I live by the Sea Summer School" and the "Ocean of Changes workshops" (numbers of participants/viewers).

\begin{tabular}{lcc}
\hline & $\begin{array}{c}\text { Number of } \\
\text { participants }\end{array}$ & $\begin{array}{c}\text { Estimated } \\
\text { outreach }\end{array}$ \\
\hline $\begin{array}{l}\text { Ocean of changes } \\
\text { (http://www.iopan.gda.pl/odn2019/ }\end{array}$ & $296+274=570$ & c. 4,500 \\
sdn/index-eng.html) & & \\
I live by the Sea Summer School & c. 50 (live) & $\begin{array}{c}\text { c. } 13,000 \\
\text { 2020 (http: }\end{array}$ \\
//www.todaywehave.com/l_live_ & & \\
by_the_Sea_Summer_School.html) & & \\
\hline
\end{tabular}

Greater outreach could be achieved through partnerships with other institutions, organizations or businesses. An example of this is a partnership between the Institute of Oceanology of the Polish Academy of Sciences (IO PAN) and Storware, a company that provides digital backup and recovery products ${ }^{14}$. Storware supports the Institute by making its software available pro bono, through jointly developing articles, or publishing content related to IOPANs' activities in its social media channels (thereby increasing this institution's visibility in the media).

\section{Examples of Good Practices in Delivery of Climate/Ocean Knowledge to General Public}

Children and teenagers, the age groups that will have been exposed to the effects of climate change the longest, are the most active social media users. Children of ages between 7 and 9 are also most likely to create personal bonds with nature (Donert, 2018; Fauville et al., 2018). It is, however, important that communicating science-based facts does not focus entirely on non-positive messaging or information that could potentially be distressing, but also provides "bright spots" (e.g., Cinner et al., 2016) and positive pathways for delivering solutions to issues (e.g., Ferrero et al., 2013, 2015; Gaines et al., 2018). Science communicators should promote societal values, e.g., social inclusion, good practices and participation through the process of planning of science communication actions (Jensen and Gerber, 2020). The widespread use of social media provides an opportunity for delivery of scientific based information to young learners and university students (Donert, 2018).

Previous analyses have shown that the Polish educational system does not devote much space to the knowledge of the seas, oceans and climate change (Kotynska-Zielinska et al., 2020), and education systems in other countries present the same features ${ }^{15}$. However, the situation is changing in some countries. Climate change issues are being introduced into the curriculum of a number of schools in Great Britain, although this introduction is not systematic as yet ${ }^{16}$. Beginning in September 2020, a curriculum of compulsory lessons

\footnotetext{
${ }^{14} \mathrm{https}: / /$ storware.eu

${ }^{15}$ https://www.theguardian.com/education/2020/feb/11/the-nationalcurriculum-barely-mentions- the-climate-crisis-children-deserve-better

${ }^{16}$ https://www.youthpolicy.org/blog/sustainability/educating-for-change/
}

for school students of ages 6 to 19 is being introduced across Italy. This, will include $33 \mathrm{~h}$ of climate change and sustainable development related topics per annum ${ }^{17}$. This curriculum has been developed through consultations with climate change experts. These experts also serve as reviewers of the curriculum and its implementation in the school system.

Systematic changes to educational curricula are also planned across New Zealand to include access to information on climate change ${ }^{18}$. All schools will have access to educational materials prepared by leading research institutions in the country. Lessons detailing climate change issues and topics will be focused toward students aged 11-15, and will be offered as optional subjects.

Popular, social media platforms, websites, blogs, and forums are only a small fraction of what modern, generally accessible media offer nowadays; they provide widespread opportunities for dissemination of information.

Non-profit organizations' profiles have been particularly effective in distributing information on climate and ocean issues via internet and social media platforms. One such example is Oceana, an international non-profit organization dedicated to protecting and revitalizing the world's ocean ${ }^{19}$. The organization has more than one million followers on Facebook, 2.6 million on Instagram and nearly 400, 000 followers on Twitter and publishes numerous posts across the platforms each day. Oceana undertakes outreach into specific countries through its regional sites (e.g., Chile, Philippines, Belize, Brazil), with content written in the most popular language in each region.

Other non-profit organizations such as SeaShepherd ${ }^{20}$, the Ocean Conservancy ${ }^{21}$, and the Project Aware ${ }^{22}$, EU4Ocean ${ }^{23}$ facilitate outreach through the involvement of volunteers, ambassadors, and committed communities that contribute to activities undertaken by the organizations. Such networks allow for broader distribution of information through sharing of content and documentation of actions and activities undertaken by the organizations. The extent of outreach of selected ocean related non-profit and for-profit organizations via social media is presented in Table 4.

Effective, yet engaging communication is mainly based on two strong pillars-an appropriate message and the platform on which it is published. The regularity of publication and frequency is also important. Common tools utilized by effective communicators include:

1. Websites. Having a webpage allows for positioning of content through search engine optimization and organization of content (systematizing) for utilization by

\footnotetext{
${ }^{17}$ https://www.forbes.com/sites/trevornace/2019/11/19/italy-law-to-requireclimate-change-education-in-grade-school/

${ }^{18}$ https://www.theguardian.com/world/2020/jan/13/new-zealand-schools-toteach-students-about-climate-crisis-activism-and-eco-anxiety

${ }^{19}$ www.oceana.org

${ }^{20}$ https://seasheperd.org

${ }^{21}$ https://oceanconservancy.org/

${ }^{22}$ https://www.projectaware.org/

${ }^{23}$ https://webgate.ec.europa.eu/maritimeforum/en/
} 
TABLE 4 | Outreach of selected ocean related non-profit and for-profit organizations via social media.

\begin{tabular}{|c|c|c|c|}
\hline Organization & $\begin{array}{l}\text { FB (approx. number of } \\
\text { followers/publication frequency/ } \\
\text { number of reactions under post) }\end{array}$ & $\begin{array}{l}\text { Instagram (approx. number of } \\
\text { followers/publication frequency/ number } \\
\text { of reactions under post) }\end{array}$ & $\begin{array}{l}\text { YouTube (number of } \\
\text { followers) }\end{array}$ \\
\hline Oceana (https://oceana.org/) & $1 \mathrm{M}, 3-4$ posts per day/100-600 reactions & $2.6 \mathrm{M}, 3-4$ posts per day/20,000 reactions & 26,900 \\
\hline $\begin{array}{l}\text { SeaShepherd } \\
\text { (https://seashepherd.org/) }\end{array}$ & $1 \mathrm{M}, 6$ posts per week/300-3,500 reactions & $\begin{array}{l}647,000,3 \text { posts per week } / 7,000-28,000 \\
\text { reactions }\end{array}$ & 13,400 \\
\hline $\begin{array}{l}\text { Nauka o klimacie (https: } \\
\text { //www.facebook.com/naukaoklimacie) }\end{array}$ & $\begin{array}{l}56,500, \text { c. } 2-3 \text { posts per day/11-150 } \\
\text { reactions }\end{array}$ & - & 669 \\
\hline $\begin{array}{l}\text { Ocean Conservancy } \\
\text { (https://oceanconservancy.org/) }\end{array}$ & $1 \mathrm{M}, 1$ post per day/120-3,000 reactions & $\begin{array}{l}\text { 370,000, } 3 \text { posts per week/each post reach } \\
\text { approx. 1,200-8,000 reactions }\end{array}$ & 2,670 \\
\hline Surfrider (https://www.surfrider.org) & $304,000,1$ post per day/20-150 reactions & $193,000,1$ post per day/1,000-5,000 reactions & 3,670 \\
\hline $\begin{array}{l}\text { Project Aware } \\
\text { (https://www.projectaware.org/) }\end{array}$ & $235,000,1$ post per day/50-130 reactions & $\begin{array}{l}\text { 168,000, } 6-7 \text { posts per week/150,000-3,000 } \\
\text { reactions }\end{array}$ & 3,090 \\
\hline $\begin{array}{l}\text { Oceanic Preservation Society } \\
\text { (https://www.opsociety.org/) }\end{array}$ & $179,000 / 4$ posts per day/30-150 reactions & $\begin{array}{l}210,000,7 \text { posts per week/500-4,000 } \\
\text { reactions }\end{array}$ & 5,690 followers \\
\hline 4ocean (https://www.4ocean.com) & 1.3M, 1 post per day/273-1,700 reactions & $2.1 \mathrm{M}, 1$ post per day $/ 20,000-85,000$ reactions & 100,000 followers \\
\hline $\begin{array}{l}\text { EU4Ocean Platform (https://webgate. } \\
\text { ec.europa.eu/maritimeforum/en/) }\end{array}$ & $\begin{array}{l}\text { Project has been launched on } 25 \\
\text { September } 2020\end{array}$ & $\begin{array}{l}\text { Project has been launched on } 25 \text { September } \\
2020\end{array}$ & $\begin{array}{l}\text { Project has been } \\
\text { launched on } 25 \\
\text { September } 2020\end{array}$ \\
\hline
\end{tabular}

Data as of 4 October 2020.

the public as well as archival of content beyond the life span of social media channels, whose content life span is relatively short.

2. Profiles on the most popular social media platforms (Facebook, Instagram, YouTube, Twitter, Pinterest, LinkedIn) with both a global and regional focus, with content refreshed multiple times a week. Selected types of content include:

- static content - posts, photos, republications, articles, graphics,

- dynamic content - films, short video forms, stories.

3. Educational and information campaigns, both offline and online.

4. Ambassadors with strong support for the message emitted in the mentioned channels. Well-known people with an interest in a topic can bring strong support for an organization's activities and further outreach through promoting these activities on their profiles. The authority provided by ambassadors adds credibility to the information, and allows for the building of a community of engaged recipients.

5. Involvement of enthusiastic volunteers that can support content creation including providing photography and graphics.

6. Partnerships with organizations that can provide products or experts pro bono for activities (e.g., diving centers, diving communities, communities of water sportsmen, etc.).

7. Support from funders (e.g., through sponsorships, grants, etc.). Having ready-made sponsorship packages for funders provided at a range of entry levels (i.e., small to large) can help facilitate involvement.

8. Partnerships with scientific institutions and other organizations, allowing for the sharing of reports, research results, data products and exchange and co-creation of content.

9. "Scientific marketing" as a field of communication and language science. Created in close cooperation between scientific and research institutions and institutes dealing with communication and language sciences.

The world is an ocean of data. Scientists hold knowledge that the general public does not have. The mission of scientists should be to communicate research results and conclusions clearly and legibly. Moreover, they should consider the target group's requirements, and therefore choose and apply attractive and engaging means to achieve science-based knowledge transfer. By doing so, they can raise awareness of climate and oceans issues and catalyze societal, governmental and political action focused on the mitigation and adaptation to climate and ocean changes.

\section{CONCLUSION}

Sound scientific understanding of climate and ocean processes, their interactions and observed rapid changes is fundamental for informing sustainable development. Climate and ocean studies and the knowledge created in association are crucial for predictions of the consequences of climate change, which are then necessary to design appropriate mitigation and adaptation actions. However, there is still an obvious gap between research and society resulting from a number of different factors.

First, school and university curricula are often based on dated paradigms and content that rely on the transfer of explicit knowledge (i.e., teaching using textbooks). Many broadly available modern tools could be used in the process of knowledge transfer, but are currently not in use. Students are rarely motivated to use their own experience and knowledge delivered 
is often taught out of context. Subjects related to climate change and ocean changes need to be included in regular school curricula with that curricula supported by modern and engaging materials and school courses. The educational system should shift its priority from transferring explicit knowledge to tacit knowledge. In order to facilitate such shift in the approach, more projectoriented activities should be promoted, allowing for the transfer of knowledge through experiential learning.

Second, many researchers limit the publication of their research to topical journals, and in doing so limit knowledge transfer to colleagues. As a result, outreach of their knowledge beyond the science community is limited. Further, researchers are often not willing to or are not invited to share their knowledge. When considering wider outreach, scientists often take it for granted that society understands the language of data and scientific observations, while for majority of citizens, graphs do not translate information adequately, rather pictures, short videos, or virals do. Many scientific institutions still do not have properly equipped communication teams that can deliver content beyond simple marketing schemes for attracting students. Linkages between ocean-related non-profit organizations and scientific institutions are lacking, but if expanded provide for greater opportunity for accurate knowledge transfer. We would very much welcome cooperation of research institutions and various climate/ocean related organizations to create certain "knowledge hubs," that allow for the sharing of scientific information in an effective way.

Third, global leaders and drivers of climate and ocean studies, such as the IPCC or UN Regular Process, are mostly dedicated to targeting decision makers and hence, information does not always reach beyond the desks of researchers and decision makers. Again, broader development of delivery platforms beyond these groups and into society more generally is needed. Not only should research institutions be encouraged but required by international institutions and governments to cooperate with companies and non-profit organizations in order to create

\section{REFERENCES}

Bawden, D., and Robinson, L. (2008). The dark side of information: overload, anxiety and other paradoxes and pathologies. J. Inform. Sci. 35, 180-191. doi: $10.1177 / 0165551508095781$

Beck, S. (2011). Moving beyond the linear model of expertise? IPCC and the test of adaptation. Region. Environ. Change 11, 297-306. doi: 10.1007/s10113-0100136-2

Cambridge International Examinations 2015 (2017). Cambridge International $A S$ \& $A$ Level Information Technology 9626 for Examination from 2017.

Cinner, J. E., Huchery, C., MacNeil, M. A., Graham, N. A. J., McClanahan, T. R., Maina, J., et al. (2016). Bright spots among the world's coral reefs. Nature 535, 416-419. doi: 10.1038/nature 18607

Donert, K. (2018). "School on the cloud: connecting education to the cloud for digital citizenship," in Handbook of Research on Educational Design and Cloud Computing in Modern Classroom Settings, eds K. Koutsopoulos and T. Kotsanis (Berlin: Springer).

Evans, K., Chiba, S., Bebianno, M. J., Garcia-Soto, C., Ojaveer, H., Park, C., et al. (2019). The global integrated world ocean assessment: linking observations to science and policy across multiple scales. Front. Mar. Sci. 6:298. doi: 10.3389/ fmars.2019.00298 channels for strengthening transfer of scientific knowledge to the public through:

1. Effective tools and mechanisms of sharing knowledge.

2. Certificates/trademarks of scientific institutions promoting cooperating companies and providing reliable information to the public.

3. Facilitation of effective flow of dedicated funds and strengthening the exchange of services between research institutions and individuals/organizations (commercial entities) to support scientific units, which work for the better future of the planet with focus on the quality of life of future generations.

\section{DATA AVAILABILITY STATEMENT}

The raw data supporting the conclusions of this article will be made available by the authors, without undue reservation.

\section{AUTHOR CONTRIBUTIONS}

TZ: paper concept, paper writing, and data analyses. EB and KE: paper concept. LF: paper concept and data analyses. KG and BO: data collecting. TK and PP: data collecting and data analyses. IK-Z: data collecting, data analyses, and paper writing. PM, JP, and JS: data analyses and paper writing. EP and MW: data analyses. All authors contributed to the article and approved the submitted version.

\section{ACKNOWLEDGMENTS}

We gratefully acknowledge the GEMMA Center input in the framework of Project MIUR - "Dipartimenti di Eccellenza 2018-2022”.
Fauville, G., McHugh, P., Domegan, C., Makitalo, A., Friis Mollerd, F., Papathanassiou, M., et al. (2018). Using collective intelligence to identify barriers to teaching 12-19 year olds about the ocean in Europe. Mar. Policy 91, 85-96. doi: 10.1016/j.marpol.2018.01.034

Ferrero, L., D’Angelo, L., Rovelli, G., Sangiorgi, G., Perrone, M., Moscatelli, M., et al. (2015). Determination of aerosol deliquescence and crystallization relative humidity for energy saving in free-cooled data centers. Int. J. Environ. Sci. Technol. 12, 2777-2790. doi: 10.1007/s13762-014-0680-2

Ferrero, L., Sangiorgi, G., Ferrini, B. S., Perrone, M. G., Moscatelli, M., D’Angelo, L., et al. (2013). Aerosol corrosion prevention and energy-saving strategies in the design of green data centers. Environ. Sci. Technol. 47, 3856-3864. doi: 10.1021/es304790f

Fischer, H., Amelung, D., and Said, N. (2019). The accuracy of German citizens' confidence in their climate change knowledge. Nat. Clim. Change 9, 776-780. doi: 10.1038/s41558-019-0563-0

Gaines, S. D., Costello, Ch, Owashi, B., Mangin, T., Bone, J., Molinos, J., et al. (2018). Improved fisheries management could offset many negative effects of climate change. Sci. Adv. 4:eaao1378.

Gordon Foundation (2015). Rethinking the Top of the World: Arctic Public Opinion Survey Report. Available online at: http://gordonfoundation.ca/ resource/rethinking-the-top-of-the-world-arctic-public-opinion-survey-vol-2/ doi: 10.1126/sciadv.aao1378 (accessed October, 2020). 
Heddy, B. C., and Sinatra, G. M. (2017). Transformative parents: facilitating transformative experiences and interest with a parent involvement intervention. Sci. Ed. 2017, 765-786. doi: 10.1002/sce.21292

Hedlund, G. (1994). A model of knowledge management and the $\mathrm{N}$-form corporation. Strategic Manag. J. 15, 73-90. doi: 10.1002/smj.425015100

Holliman, R., and Jensen, E. (2009). “(In)authentic science and (im)partial publics: (Re)constructing the science outreach and public engagement agenda," in Investigating Science Communication in the Information Age: Implications for Public Engagement and Popular Media, eds R. Holliman, E. Whitelegg, E. Scanlon, S. Smidt, and J. Thomas (Oxford: Oxford University Press), 35-52.

Hulme, M., and Mahony, M. (2010). Climate change: what do we know about the IPCC? Prog. Phys. Geogr. 34, 705-718.

IOC/EC-LI/2 Annex 3 (2018). Revised Roadmap for the UN Decade of Ocean Science for Sustainable Development.

IPCC (2014). “Climate change 2014: synthesis report," in Contribution of Working Groups I, II and III to the Fifth Assessment Report of the Intergovernmental Panel on Climate Change, eds Core Writing Team, R. K. Pachauri, and L. A. Meyer (Geneva: IPCC).

Jensen, E., and Gerber, A. (2020). Evidence-based science communication. Front. Commun. 4:78. doi: 10.3389/fcomm.2019.00078

Kahila, J., Valtonen, T., Tedre, M., Mäkitalo, K., and Saarikoski, O. (2020). Children's experiences on learning the 21st-century skills with digital games. Games Culture 15, 685-706. doi: 10.1177/1555412019845592

Kollmuss, A., and Agyeman, J. (2010). Mind the Gap: why do people act environmentally and what are the barriers to pro-environmental behavior? Environ. Education Res. 8, 239-260. doi: 10.1080/1350462022014 5401

Kopke, K., Black, J., and Dozier, A. (2019). Stepping out of the ivory tower for ocean literacy. Front. Mar. Sci. 6:60. doi: 10.3389/fmars.2019.00060

Kotynska-Zielinska, I., Olenin, S., Fornalewicz, K., Pradzinska, A., and Wesławski, J. M. (2020). Perception of Arctic issues among young learners in Poland and Lithuania. Oceanologia 62, 576-587. doi: 10.1016/j.oceano.2020.03.006

Koutsopoulos, K., Rafael, M., and Donert, K. (2019). Geospatial Challenges in the 21st Century. Berlin: Springer.

McCauley, V., McHugh, P., Davison, K., and Domegan, C. T. (2019). Collective intelligence for advancing ocean literacy. Environ. Edu. Res. 25, 280-291. doi: 10.1080/13504622.2018.1553234

McKinley, E., and Fletcher, S. (2012). Improving marine environmental health through marine citizenship: a call for debate. Mar. Policy 36, 839-843. doi: 10.1016/j.marpol.2011.11.001

Orr, E., Hansen, Lappalainen, G., Hübner, H., and Lihavainen, H. (eds) (2019). SESS report 2018, Svalbard Integrated Arctic Earth Observing System. Longyearbyen: SESS.

Patterson, J., Schulz, K., Vervoort, J., van der Hel, S., Widerberg, O., Adler, C., et al. (2017). Exploring the governance and politics of transformations towards sustainability. Environ. Innov. Soc. Trans. 24, 1-16. doi: 10.1016/j.eist.2016. 09.001

Pendleton, L., Evans, K., and Visbeck, M. (2020). We need a global movement to transform ocean science for a better world. Proc. Natl. Acad. Sci. U.S.A. 117, 9652-9655. doi: 10.1073/pnas.2005485117

Peters, M. A. (2020). Digital socialism or knowledge capitalism? Educ. Philos. Theory 52, 1-10. doi: 10.1080/00131857.2019.1593033

Report of the World Summit on Sustainable Development (2002a). A/CONF.199/20* United Nations publication Sales No. E.03.II.A.1 ISBN 92-1-104521-5. Johannesburg: Report of the World Summit on Sustainable Development.

Report of the World Summit on Sustainable Development (2002b). Johannesburg, South Africa, 26 August-4 September 2002; ISBN 92-1-104521-5. Johannesburg: Report of the World Summit on Sustainable Development.
Rubio-Iglesias, J. M., Edovald, T., Grew, R., Kark, T., Kideys, A. E., Peltola, T., et al. (2020). Citizen science and environmental protection agencies: engaging citizens to address key environmental challenges. Front. Clim. 2:600998. doi: 10.3389/fclim.2020.600998

Serban, A., and Luan, J. (2002). Overview of Knowledge Management. Hoboken, NJ: Wiley Periodicals, Inc.

Sibbel, A. (2009). Pathways towards sustainability through higher education. Int. J. Sustainab. High. Educ. 10, 68-82. doi: 10.1108/14676370910925262

Stoll-Kleemann, S. (2019). Feasible options for behavior change toward more effective ocean literacy: a systematic review. Front. Mar. Sci. 6:273. doi: 10.3389/ fmars.2019.00273

Sundblad, E.-L., Biel, A., and Gärling, T. (2009). Knowledge and confidence in knowledge about climate change among experts, journalists, politicians, and laypersons. Environ. Behav. 41, 281-302. doi: 10.1177/0013916508314998

Terorotua, H., Duvat, V. K. E., Maspataud, A., and Ouriqua, J. (2020). Assessing perception of climate change by representatives of public authorities and designing coastal climate services: lessons learnt from french polynesia. Front. Mar. Sci. 7:160. doi: 10.3389/fmars.2020.00160

The Millennium Development Goals Report 2014 (2014). ISBN 978 - 92-1-10130 8-5. New York, NY: The Millennium Development Goals.

UN (2017a). Technical abstract of the First Global Integrated Marine Assessment on the Ocean and the Sustainable Development Goals under the 2030 Agenda for Sustainable Development. New York, NY: United Nations.

UN (2017b). The First Global Integrated Marine Assessment. World Ocean Assessment I. United Nations. Cambridge: Cambridge University Press.

UNEP (2019). Programme Performance Report 2018. Nairobi: UNEP.

Van den Heuvel, F., Hübner, C., Błaszczyk, M., Heimann, M., and Lihavainen, H. (eds) (2020). SESS report 2019, Svalbard Integrated Arctic Earth Observing System. Longyearbyen: SESS.

Vedder-Weiss, D., and Fortus, D. (2011). Adolescents' declining motivation to learn science: Inevitable or not? J. Res. Sci. Teach. 48, 199-216. doi: 10.1002/ tea. 20398

Williamson, P. (2016). Take the time and effort to correct misinformation. Nature 540:171. doi: 10.1038/540171a

Wisz, M. S., Satterthwaite, E. V., Fudge, M., Fischer, M., Polejack, A., St. John, M., et al. (2020). 100 opportunities for more inclusive ocean research: cross-disciplinary research questions for sustainable ocean governance and management. Front. Mar. Sci. 7:576. doi: 10.3389/fmars.2020.00576

Zins, C. H. (2007). Conceptual approaches for defining data, information, and knowledge. J. Am. Soc. Inform. Sci. Tech. 58, 479-493. doi: 10.1002/asi.20508

Zusho, A., Pintrich, P. R., and Coppola, B. (2003). Skill and will: the role of motivation and cognition in the learning of college chemistry. Int. J. Sci. Educ. 25, 1081-1094. doi: 10.1080/0950069032000052207

Conflict of Interest: PM and JS were employed by Storware. IK-Z was employed by Today We Have.

The remaining authors declare that the research was conducted in the absence of any commercial or financial relationships that could be construed as a potential conflict of interest.

Copyright (c) 2021 Zielinski, Bolzacchini, Evans, Ferrero, Gregorczyk, Kijewski, Kotynska-Zielinska, Mrowiec, Oleszczuk, Pakszys, Piechowska, Piwowarczyk, Sobieszczanski and Wichorowski. This is an open-access article distributed under the terms of the Creative Commons Attribution License (CC BY). The use, distribution or reproduction in other forums is permitted, provided the original author(s) and the copyright owner(s) are credited and that the original publication in this journal is cited, in accordance with accepted academic practice. No use, distribution or reproduction is permitted which does not comply with these terms. 